\title{
Dioxin-induced acute cardiac mitochondrial oxidative damage and increased activity of ATP-sensitive potassium channels in Wistar rats
}

\author{
Susana P. Pereira ${ }^{a}$, Gonçalo C. Pereira ${ }^{a}$, Cláudia V. Pereira ${ }^{a}$, Filipa S. Carvalho ${ }^{a}$, \\ Marília H. Cordeiro a , Paula C. Mota ${ }^{a}$, João Ramalho-Santos ${ }^{\mathrm{a}}$, António J. Moreno ${ }^{\mathrm{b}}$, \\ Paulo J. Oliveira ${ }^{\mathrm{a}, *}$ \\ ${ }^{a}$ CNC - Center for Neuroscience and Cell Biology, University of Coimbra, Largo Marquês de Pombal, 3004-517 Coimbra, Portugal \\ ${ }^{\mathrm{b}}$ Institute for Marine Research, Department of Life Sciences, University of Coimbra, Coimbra, Portugal
}

\section{A R T I C L E I N F O}

Article history:

Received 3 December 2012

Received in revised form

25 May 2013

Accepted 29 May 2013

\section{Keywords:}

Bioenergetics

Dioxin

mitoKATP

Mitochondria

ROS

TCDD

\begin{abstract}
A B S T R A C T
The environmental dioxin 2,3,7,8-Tetrachlorodibenzo-p-dioxin (TCDD) is classified as a Group 1 human carcinogen and teratogenic agent. We hypothesize that TCDD-induced oxidative stress may also interfere with mitochondrial ATP-sensitive potassium channels (mitoKATP), which are known to regulate and to be regulated by mitochondrial redox state. We investigated the effects of an acute treatment of male Wistar rats with TCDD (50 $\mu \mathrm{g} / \mathrm{kg}$ i.p.) and measured the regulation of cardiac mitoKATP. While the function of cardiac mitochondria was slightly depressed, mitoKATP activity was 52\% higher in animals treated with TCDD. The same effects were not observed in liver mitochondria isolated from the same animals. Our data also shows that regulation of mitochondrial ROS production by mitoKATP activity is different in both groups. To our knowledge, this is the first report to show that TCDD increases mitoKATP activity in the heart, which may counteract the increased oxidative stress caused by the dioxin during acute exposure.
\end{abstract}

(C) 2013 Elsevier Ltd. All rights reserved.

\section{Introduction}

The very persistent environmental toxin 2,3,7,8-Tetrachlorodibenzo-p-dioxin (TCDD) harbors a low breakdown rate; in fact, this dioxin is omnipresent in the global environment and has an estimated half-life of 7.6 years in humans (Michalek and Tripathi, 1999). The US Environmental Protection Agency (EPA) has estimated that more than $90 \%$ of total human exposure to dioxins and dioxin-like compounds - polychlorinated dibenzop-dioxins and polychlorinated dibenzofurans (PCDD/Fs) - occurs through food consumption (U.S. EPA. Dioxin Reassessment.

Abbreviations: 5-HD, 5-hydroxydecanoic acid; ADP, adenosine diphosphate; AhR, aromatic hydrocarbon receptor; ATP, adenosine triphosphate; BSA, bovine serum albumin; $\Delta \Psi$, mitochondrial transmembrane electric potential; DMSO, dimethylsulphoxide; DNA, deoxyribonucleic acid; DNPH, dinitrophenylhydrazine; DZX, Diazoxide; HEPES, 4-(2-hydroxyethyl)-1-piperazineethanesulfonic acid; HRP, horseradish peroxidase type vi-a; HW/BW, heart weight/body weight; LW/BW, liver weight/body weight; mitoKATP, mitochondrial ATP-sensitive potassium channels; $\mathrm{PCDD} / \mathrm{Fs}$, polychlorinated dibenzofuran; RCR, respiratory control ratio; ROS, reactive oxygen species; SDS, sodium dodecyl sulfate; TCDD, 2,3,7,8-Tetrachlorodibenzo-pdioxin; TFA, trifluoroacetic acid; TPP ${ }^{+}$, tetraphenylphosphonium cation.

* Corresponding author.

E-mail address: pauloliv@ci.uc.pt (P.J. Oliveira).
National Academy of Sciences (NAS) Review Draft 2004. U.S. Environmental Protection Agency, 2004), although water and, to a lesser extent, inhalation and skin absorption can also be exposure sources (Mandal, 2005). PCDD/Fs can also originate from natural sources such as forest fires; however, the more significant origins of dioxins include waste incineration, pesticide manufacture, chlorine bleaching of pulp and paper, municipal and industrial incineration, and metal refining (Hays and Aylward, 2003).

Low doses of TCDD administered to rodents by different routes cause tumors at multiples sites (Knerr and Schrenk, 2006). Different mechanisms have been proposed for the carcinogenic effect of TCDD, including binding and activation of the cytosolic aromatic hydrocarbon receptor (AhR) (Ray and Swanson, 2009), a ligand-activated nuclear transcription factor. Also, TCDD increases reactive oxygen species (ROS) generation, which results in lipid peroxidation, leading to cell membrane disruption, DNA and protein damage and calcium homeostasis disruption in various rodent tissues (Aly and Khafagy, 2011; Hassoun et al., 2000; Shertzer et al., 2006). Generation of ROS such as hydroxyl radical, superoxide anion and hydrogen peroxide appear to be involved in TCCDinduced oxidative damage (Stohs et al., 1986).

Mitochondria may mediate, at least in part, TCDD-induced oxidative stress effects. Nohl et al. (1989) demonstrated that 
superoxide anion and hydrogen peroxide are produced following in vitro addition of TCDD to bovine heart mitochondria (Nohl et al., 1989). Exposure of C2C12 myocytes to TCDD results in inhibition of mitochondrial transcription, disruption of mitochondrial transmembrane potential $(\Delta \Psi)$ and altered calcium homeostasis (Biswas et al., 2008). In addition to developing an increased resistance to apoptosis, TCDD-treated C2C12 cells also acquired increased invasive capacity, none of the effects being dependent on the AhR (Biswas et al., 2008). These findings suggest that TCDD toxicity may present a mitochondrial component. In fact, mitochondria are a plausible target for several xenobiotics and an excellent in vitro model to predict compound toxicity (Pereira et al., 2009).

The mitochondrial $\mathrm{K}^{+}$cycle consists of electrophoretic $\mathrm{K}^{+}$uptake and electroneutral $\mathrm{K}^{+}$efflux across the inner membrane (Garlid, 1996), the latter being mediated by a $\mathrm{K}^{+} / \mathrm{H}^{+}$antiporter and influx is mediated by a mitochondrial ATP-sensitive potassium channels (mitoKATP) (Garlid, 1996). Other potassium channels are present in the inner mitochondrial membrane including a large conductance $\mathrm{Ca}^{2+}$-activated potassium channel (Siemen et al., 1999), the voltagegated Kv1.3 potassium channel (Szabo et al., 2005) and the twinpore domain TASK-3 potassium channel (Rusznak et al., 2008). The putative functional roles of these several channels include the modulation of mitochondrial matrix volume, respiration and membrane potential (Szewczyk et al., 2009). In addition, the activity of these channels can also modulate the generation of reactive oxygen species (ROS) by mitochondria (Facundo et al., 2007). The molecular identity of mammalian mitoKATP is a matter of debate. ATP-sensitive $\mathrm{K}^{+}$(KATP) channels were initially identified in the plasma membrane of cardiac myocytes (Noma, 1983). These channels were further distinguished by their specific localization within the cell. Sarcolemmal (sarcKATP), nuclear (nucKATP) or mitochondrial (mitoKATP) ATP sensitive potassium channels have been identified. Although the mitoKATP was characterized (Inoue et al., 1991) and later purified and partly reconstituted (Paucek et al., 1992), their composition and nature is still debatable. Many research groups propose that the channel has a structure similar to classical KATP channels, based on the pharmacological sensitivities and immunoreactivity with specific antibodies. Also, it has been suggested that the mitoKATP from rats heart include a $\mathrm{K}^{+}$inward rectifier (mitoKIR, subunits Kir6.1 and Kirb 6.2) and sulfonylurea receptors (SURs, namely SUR2) (Cuong et al., 2005; Suzuki et al., 1997).

The modulation of mitoKATP (O'Rourke, 2004) by pro-oxidant xenobiotics with environmental relevance has received scarce attention. The putative functional roles of mitoKATP include modulation of mitochondrial matrix volume, mitochondrial respiration and membrane potential. The activity of mitoKATP can also modulate the generation of ROS by mitochondria (Szewczyk et al., 2009).

Kowaltowski and co-workers proposed mitoKATP openers to have direct effects on mitochondrial respiration, membrane potential and $\mathrm{Ca}^{2+}$ uptake under physiological conditions (Kowaltowski et al., 2001). MitoKATP are redox-sensitive channels with higher activity under increasingly oxidative conditions (Facundo et al., 2007; Liu et al., 2002), suggesting a role of this channel in redox mitochondrial signalling in the heart, where higher activity of this channel has been described (Kowaltowski et al., 2001).

The hypothesis for the present work is that an acute TCDD treatment causes oxidative damage to cardiac mitochondria resulting not only in mitochondrial damage, but also in an altered regulation of mitoKATP. Our hypothesis includes that increased activation of mitoKATP would counteract TCDD-induced oxidative stress and prevent further mitochondrial damage. The heart was focused in the present work since the mitoKATP are an important component of different cardiac signalling pathways that respond to alterations in the redox state of the cell. One such pathway with clinical relevance involves KATP on ischemic pre-conditioning (Queliconi et al., 2011).

\section{Material and methods}

\subsection{Reagents}

All reagents used were of the highest grade of purity commercially available (analytical grade or better), and all aqueous solutions were prepared in ultrapure (type I) water. A 99\% chemical pure TCDD (2,3,7,8-tetrachlorodibenzo-p-dioxin) from LGC Standards (Barcelona, Spain) was dissolved in dimethylsulphoxide (DMSO) $66.7 \mu \mathrm{g} / \mathrm{ml}$. Diazoxide (DZX, in DMSO), 5-hydroxydecanoic acid (5-HD, in water) stock solutions were prepared just prior to each experiment. Amplex Red (in DMSO) and horseradish peroxidase type VI-A (HRP) provided by Sigma-Aldrich, St. Louis MO, USA, rotenone (in DMSO), adenosine triphosphate (ATP, in water), glutamate/ malate and succinate (in water) solutions were kept as frozen aliquots.

For Western blotting assays, the primary antibody used was Rabbit Anti-DNP (D9656) from Sigma (Portugal). The secondary antibody was Goat anti-rabbit IgGAP (sc-2007) from Santa Cruz Biotechnology Inc. (Portugal). The protein molecular weight markers (Precision Plus Protein Dual Color Standards) were obtained from Bio-Rad Laboratories, Inc., CA, USA, while the ECF substrate was obtained from Amersham Biosciences, Buckinghamshire, England.

\subsection{Animal care and ethical statement}

All experiments involving animals were conducted in accordance with the European convention for the protection of vertebrate animal used for experimenta and other scientific purposes (CETS no. 123 of 18 march 1986 and 2005 revision) and the Commission Recommendation of 18 June 2007 on guidelines for the accommodation and care of animals used for experimental and other scientific purposes (C (2007) 2525). The authors are accredited by the Federation of Laboratory Animal Science Associations (FELASA) for animal experimentation. A limited number of animals were used in the present study based on preliminary data obtained for liver mitochondria and due to concerns in the use of a larger pool of animals with this particular environmental toxicant. Male Wistar Han IGS rats were purchased from Charles River (France). Animals were group-housed in type III-H cages (Tecniplast, Italy) with appropriated corn cob bedding and environmental enrichment. Rats were maintained in proper environmental requirements including room temperature set at $22{ }^{\circ} \mathrm{C}$, relative humidity at $45-65 \%$, ventilation with $15-20$ changes/hour, a12 h light/dark cycle, noise level $<55 \mathrm{~dB}$, and ad libitum access to standard rodent food (4RF21 GLP certificate, Mucedola, Italy) and acidified water (at pH 2.6 with $\mathrm{HCl}$, in order to prevent bacterial growth). All animals were acclimated 10-14 days prior to experiment initiation. For the current study, 10 week old rats (280-350 g) were injected with TCDD (50 $\mu \mathrm{g} / \mathrm{kg}$ of body weight) in DMSO or with an equivalent volume of DMSO alone (controls) via intraperitoneal injection (i.p.), $24 \mathrm{~h}$ before the sacrifice. All animals were weighed at the beginning and end of the experimental period. This dosing protocol was chosen based on previous studies (Choi et al., 2008; Stohs et al., 1991). Non-fasted rats were euthanized by cervical dislocation between 9:00 and 10:00 AM to eliminate possible effects due to diurnal variation. Hearts (about $0.8 \mathrm{~g}$ ) and livers (about $10.0 \mathrm{~g}$ ) were removed, weighed and placed in chilled isolation medium containing $300 \mathrm{mM}$ sucrose, $10 \mathrm{mM}$ HEPES-KOH (7.2), 1 mM EGTA and $1 \mathrm{mg} / \mathrm{ml}$ fatty acid free BSA.

\subsection{Isolation of the cardiac mitochondrial fraction}

Heart mitochondria were isolated from male Wistar rats (10 weeks old) as previously described (Oliveira et al., 2001). After weighing, the hearts were immediately excised and finely minced in an ice-cold isolation medium, with blood removed. Minced blood-free tissue was then resuspended in $40 \mathrm{ml}$ of isolation medium supplied with $0.2 \mathrm{mg}$ protease Type VIII (Sigma $\left.\mathrm{n}^{\circ} \mathrm{P}-5390\right)$ per gram of tissue and homogenized with a tightly-fitted homogenizer (Teflon pestle:glass homogenizer) for $2-3 \mathrm{~min}$ in order to minimize loss of mitochondrial membrane integrity. The suspension was incubated for $1 \mathrm{~min}\left(4^{\circ} \mathrm{C}\right)$ and then re-homogenized. The protease was then removed from the homogenate by centrifugation at $14,400 \times$ $\mathrm{g}$ for $5 \mathrm{~min}$ at $4{ }^{\circ} \mathrm{C}$. The supernatant was decanted and the pellet, essentially free of protease, was gently homogenized to its original volume with a loose-fitting homogenizer. The suspension was centrifuged at $750 \times \mathrm{g}$ for $10 \mathrm{~min}$ and the resulting supernatant was centrifuged at $12,000 \times g$ for $10 \mathrm{~min}$ with washing medium (300 mM sucrose, $10 \mathrm{mM}$ HEPES-KOH (7.2)). The pellet was resuspended manually using a paintbrush and washed twice at $12,000 \times \mathrm{g}$ for $10 \mathrm{~min}$, being then resuspended in $500 \mu \mathrm{L}$ of washing medium. Mitochondrial protein content was determined by the Biuret method (Gornall et al., 1949) using BSA as standard. Mitochondrial yield was also calculated as the mitochondrial protein obtained divided by heart weight $(\times 100)$ and expressed in percentage (\%). Samples were kept on ice and used within $1 \mathrm{~h}$ of isolation to ensure mitoKATP activity and pharmacological regulation.

\subsection{Detection of mitochondrial carbonyl groups}

The protein reactive carbonyls in mitochondrial fraction were analyzed according to previously published methods (Robinson et al., 1999) with slight modifications. A determined volume of mitochondrial suspension (V) containing 
$50 \mu \mathrm{g}$ of protein was derivatized with dinitrophenylhydrazine (DNPH). For this purpose, a volume (1V) of $12 \%$ sodium dodecyl sulfate (SDS) and two volumes (2V) of $20 \mathrm{mM}$ DNPH prepared in 10\% TFA was added to each sample, followed by a $20 \mathrm{~min}$ incubation in the dark. After this period, a neutralization reaction with 1.5 volumes $(1.5 \mathrm{~V})$ of $2 \mathrm{M}$ Tris and $18 \%$ of $\beta$-mercaptoethanol was performed. A negative control with $20 \mathrm{mM} \mathrm{NaBH}_{4}$, which reduces carbonyl groups to alcohols, was simultaneously prepared for each sample. After dilution in Tris buffer solution to obtain a final concentration of $0.1 \mu \mathrm{g} / \mu \mathrm{l}, 5 \mu \mathrm{g}$ mitochondrial protein were loaded into a $12 \%$ polyacrylamide gel using SDS-PAGE electrophoresis and probed against protein carbonyl groups (anti-DNP, 1:2500 overnight at $4{ }^{\circ} \mathrm{C}$ ).

\subsection{Mitochondrial respiratory activity}

Oxygen consumption of isolated mitochondria was monitored polarographically with a Clark-type oxygen electrode connected to a suitable recorder. The suspension was under controlled temperature $\left(37^{\circ} \mathrm{C}\right)$ and constant stirring in $1 \mathrm{~mL}$ of reaction

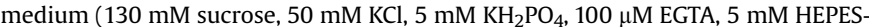
$\mathrm{KOH} \mathrm{pH} \mathrm{7.4)} \mathrm{in} \mathrm{a} \mathrm{thermostatic} \mathrm{water-injected} \mathrm{closed} \mathrm{chamber.} \mathrm{Mitochondria}$ $(0.5 \mathrm{mg}$ ) were incubated for $1 \mathrm{~min}$ and energized with either $2 \mathrm{mM}$ of glutamate/ malate or $2 \mathrm{mM}$ of succinate plus $3 \mu \mathrm{M}$ rotenone. After reaching steady-state oxygen consumption, $100 \mathrm{nmol}$ ADP was added to initiate state 3 respiration.

The respiratory control ratio (RCR), an indication of mitochondrial integrity, and the $\mathrm{ADP} / \mathrm{O}$ ratio, a measure of the efficiency of the phosphorylation system, were calculated as described previously (Chance and Williams, 1955).

\subsection{Determination of mitochondrial transmembrane potential $(\Delta \Psi)$}

The $\Delta \Psi$ was indirectly estimated by evaluating the transmembrane distribution of the lipophilic cation tetraphenylphosphonium $\left(\mathrm{TPP}^{+}\right)$using a $\mathrm{TPP}^{+}$selective electrode in combination with an $\mathrm{Ag} / \mathrm{AgCl}$ saturated reference electrode as previously described (Oliveira et al., 2000). Both the $\mathrm{TPP}^{+}$electrode and the reference electrode were inserted into a chamber at $37^{\circ} \mathrm{C}$ with magnetic stirring in $1 \mathrm{~mL}$ of

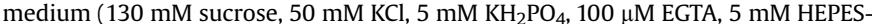
$\mathrm{KOH} \mathrm{pH}$ 7.4) containing $3 \mu \mathrm{M} \mathrm{TPP}-\mathrm{Cl}$. The $\Delta \Psi$ (in $\mathrm{mV}$ ) was estimated without any binding correction, according to Kamo et al. (Kamo et al., 1979) and as previously described (Sardao et al., 2002). Mitochondria $(0.5 \mathrm{mg}$ ) were incubated for $1 \mathrm{~min}$ and energized with $2 \mathrm{mM}$ of glutamate/malate or $2 \mathrm{mM}$ of succinate plus $3 \mu \mathrm{M}$ rotenone. After reaching a steady-state distribution of $\mathrm{TPP}^{+}, 100 \mathrm{nmol}$ ADP was added and $\Delta \Psi$ fluctuations were recorded. To confirm state 3 respiration results, the phosphorylative lag-phase was also calculated as the time in seconds taken by the mitochondrial suspension to phosphorylate the added ADP and restore the basal $\Delta \Psi$ values.

2.7. Measurement of mitochondrial matrix volume changes modulating the mitoKATP activity

Light-scattering changes due to $\mathrm{K}^{+}$uptake and swelling in mitochondrial suspensions (Kowaltowski et al., 2001; Facundo et al., 2007) were followed over time using a Perkin Elmer LS-55B Fluorescence Spectrometer operating with excitation and emission wavelengths both set at $520 \mathrm{~nm}$ and slit widths of $2.5 \mathrm{~nm}$ with continuous stirring at $37^{\circ} \mathrm{C}$. Mitochondria $(0.25 \mathrm{mg}$ protein $/ \mathrm{ml})$ were suspended in a buffered salt medium containing $130 \mathrm{mM} \mathrm{KCl}, 2 \mathrm{mM} \mathrm{KH}_{2} \mathrm{PO}_{4}, 2.5 \mathrm{mM} \mathrm{MgCl} 2$ and 10 mM HEPES-KOH pH 7.2 or in media in which all $\mathrm{K}^{+}$salts were substituted by $\mathrm{Na}^{+}$. Except for basal assays, mitochondria were energized with $2 \mathrm{mM}$ succinate and $1 \mu \mathrm{g} / \mathrm{ml}$ oligomycin was included to inhibit $\Delta \Psi$ variations resulting from ATP synthesis by the $\mathrm{F}_{0} \mathrm{~F}_{1}$-ATP synthase, as well as regulation of mitochondrial ROS production by this enzyme (Shertzer et al., 2006; Veenman et al., 2010). In some experiments, $3 \mu \mathrm{M}$ rotenone was added to inhibit reverse electron transfer from complex succinate-reduced II to complex I. Additionally, 1 mM ATP, $150 \mu \mathrm{M}$ 5-HD and/or $30 \mu \mathrm{M}$ DZX were also added to the reaction buffer (please see table and figure legends for further details). When used, DZX was added to the suspension $2 \mathrm{~s}$ after mitochondria to ensure an even media distribution. It should also be noted that DZX is ineffective unless ATP is already present, because a channel opener will not act on an already open channel (Facundo et al., 2007). Similarly, 5-HD is ineffective unless ATP and a channel opener, such as DZX, are already present because 5-HD alone does not block the channel, but rather prevents the effect of diazoxide (Jaburek et al., 1998). Light-scattering recordings were initiated by the addition of mitochondria and followed for more than $200 \mathrm{~s}$. Data was analyzed using the software FL WinLab provided by the manufacturer (PerkinElmer Life and Analytical Sciences, Boston, MA).

\subsection{Measurement of hydrogen peroxide production}

The production of $\mathrm{H}_{2} \mathrm{O}_{2}$ by the respiratory chain and modulation by mitoKATP was evaluated fluorometrically using the fluorescent probe Amplex Red, as described previously (Facundo et al., 2007; Zhou et al., 1997) with some modifications. Briefly, Amplex Red (Sigma-Aldrich, St. Louis, MO) was dissolved in DMSO to achieve a concentration of $10 \mathrm{mM}$; horseradish peroxidase type VI-A (HRP, SigmaAldrich, St. Louis, MO) was prepared in reaction buffer ( $130 \mathrm{mM} \mathrm{KCl}, 2 \mathrm{mM} \mathrm{KH_{2 }} \mathrm{PO}_{4}$
$2.5 \mathrm{mM} \mathrm{MgCl}_{2}$ and $10 \mathrm{mM}$ HEPES-KOH pH 7.2 or in media in which all $\mathrm{K}^{+}$salts were substituted by $\mathrm{Na}^{+}$) to a final concentration of $1550 \mathrm{U} / \mathrm{ml}$, and were kept at $4{ }^{\circ} \mathrm{C}$ through the end of the experiments. All experiments were conducted in duplicate using a Costar 96 wells black clear-bottom microplate (Corning, NY) with $100 \mu \mathrm{g}$ protein, $5 \mu \mathrm{M}$ Amplex Red, $1 \mathrm{U} / \mathrm{L}$ peroxidase, $1 \mathrm{ug} / \mathrm{mL}$ oligomycin and supplemented with $200 \mu \mathrm{L}$ buffer per well. Depending on the assay, $2 \mathrm{mM}$ succinate, $1 \mathrm{mM}$ ATP, $150 \mu \mathrm{M} 5$-HD and/or $30 \mu \mathrm{M}$ DZX were added to the reaction medium. Sample fluorescence was then followed for $10 \mathrm{~min}$ in intervals of $25 \mathrm{~s}$ at $37^{\circ} \mathrm{C}$ in a SpectraMax Gemini EM Fluorescence microplate reader (Molecular Devices, Sunnyvale, CA) with $563 \mathrm{~nm}$ excitation and $587 \mathrm{~nm}$ emission wavelengths ( $570 \mathrm{~nm}$ cut-off). The rates of $\mathrm{H}_{2} \mathrm{O}_{2}$ production by rat heart mitochondria were obtained from the initial slopes determined using software provided by the manufacturer (SoftMax Pro version 5.0) and are plotted as fluorescence arbitrary units per second (A.U./s).

\subsection{Data analyses and statistics}

Data are presented as mean \pm SEM of three to five experiments conducted with different and independents mitochondrial preparations. Comparisons between control and treated were conducted using a Student's $t$-test (one variable) or using one-way ANOVA followed by specifics Bonferroni multiple comparison tests. Differences were considered significant if: ${ }^{*} p<0.05$; ${ }^{* *} p<0.01$ and ${ }^{* * *} p<0.001$. Statistical analyses were performed using Graph Pad Prism version 5.

\section{Results}

\subsection{Body and organs weight did not change in response of TCDD}

After a single dose of $50 \mu \mathrm{g}$ TCDD/kg body weight, no alterations were observed in male Wistar rats body weight $24 \mathrm{~h}$ posttreatment (Supplementary Table 1). The heart and liver weights of treated animals did not differ from control animals which resulted in unchanged organ weight/body weight (HW/BW and LW/BW). Blood glucose was measured prior to the injections and right before animal sacrifice. No alterations were found between groups (Supplementary Table 1). Data also shows that acute treatment with TCDD did not alter cardiac mitochondrial isolation yield.

\subsection{Effects of TCDD on cardiac and hepatic mitochondrial bioenergetics}

Oxygen consumption data on glutamate/malate- and succinateenergized cardiac and liver mitochondria from control and treatedanimals are presented in Table 1 . In the heart, a decrease in the RCR value with glutamate-malate as mitochondrial substrate was observed as a result of TCDD treatment $(3.8 \pm 0.4$ vs $2.7 \pm 0.4$, $p=0.03$ ), although no differences were found with succinate as substrate $(2.3 \pm 0.2$ vs $1.8 \pm 0.1, p=0.14)$. Statistically significant differences were also found in the ADP/O ratio in heart mitochondria with the TCDD group having a lower value, but only when succinate was used as substrate $(2.1 \pm 0.2 \mathrm{nmolADP} /$ natmsO vs $1.7 \pm 0.3 \mathrm{nmolADP} /$ natmsO, $p=0.04)$.

Interestingly, as opposed to the slight deterioration of cardiac mitochondrial respiration, an apparent improvement in liver mitochondrial function after TCDD was found (Table 1), characterized by a significant increase in both state 3 (succinate, $205.0 \pm 46.7$ natms $\mathrm{O} / \mathrm{min} / \mathrm{mg}$ prot $v s 320.8 \pm 22.9$ natms $\mathrm{O} / \mathrm{min} /$ mg prot, $p=0.04$ ) and RCR (both substrates, for glutamate $4.6 \pm 0.3$ vs $6.6 \pm 0.3 p=0.006$ and for succinate $4.9 \pm 0.5$ vs $6.1 \pm 0.2$, $p=0.03$ ). Also, decreased state 2 respiration was found in liver mitochondria from TCDD-treated animals, when glutamate-malate was used as substrate $(43.1 \pm 5.1$ natms $\mathrm{O} / \mathrm{min} / \mathrm{mg}$ prot $v s$ $34.8 \pm 3.6$ natms $\mathrm{O} / \mathrm{min} / \mathrm{mg}$ prot, $p=0.03$ ).

Cardiac mitochondria from DMSO-treated animals developed a $\Delta \Psi$ around $220 \mathrm{mV}$ (negative inside) after energization (Fig. 1). TCDD treatment decreased maximal $\Delta \Psi$ generated by cardiac mitochondria and caused an overall increase in liver mitochondria. Nevertheless, the differences did not reach statistical significance 
Table 1

Respiratory parameters in energized cardiac and hepatic rat mitochondria in the different experimental groups.

\begin{tabular}{|c|c|c|c|c|c|c|c|c|}
\hline & \multicolumn{4}{|c|}{ Glutamate/malate } & \multicolumn{4}{|l|}{ Succinate } \\
\hline & \multicolumn{2}{|l|}{ Heart } & \multicolumn{2}{|l|}{ Liver } & \multicolumn{2}{|l|}{ Heart } & \multicolumn{2}{|l|}{ Liver } \\
\hline & Control & TCDD & Control & TCDD & Control & TCDD & Control & TCDD \\
\hline State 2 (natms $\mathrm{O} / \mathrm{min} / \mathrm{mg}$ prot) & $76.2 \pm 15.6$ & $67.0 \pm 11.3$ & $43.1 \pm 5.1$ & $34.8 \pm 3.6^{*}$ & $152.0 \pm 28.1$ & $123.0 \pm 15.0$ & $42.2 \pm 8.1$ & $47.9 \pm 2.9$ \\
\hline State 3 (natms $\mathrm{O} / \mathrm{min} / \mathrm{mg}$ prot) & $243.4 \pm 9.9$ & $189.5 \pm 24.1$ & $194.9 \pm 17.8$ & $216.5 \pm 22.5$ & $354.5 \pm 39.5$ & $322.5 \pm 33.6$ & $205.0 \pm 46.7$ & $320.8 \pm 22.9^{*}$ \\
\hline State 4 (natms $\mathrm{O} / \mathrm{min} / \mathrm{mg}$ prot) & $72.6 \pm 17.4$ & $73.3 \pm 13.9$ & $43.2 \pm 7.2$ & $33.0 \pm 4.6$ & $167.7 \pm 37.2$ & $184.1 \pm 23.3$ & $43.9 \pm 4.6$ & $53.0 \pm 3.3$ \\
\hline RCR & $3.8 \pm 0.4$ & $2.7 \pm 0.4^{*}$ & $4.6 \pm 0.3$ & $6.6 \pm 0.3^{* *}$ & $2.3 \pm 0.2$ & $1.8 \pm 0.1$ & $4.9 \pm 0.5$ & $6.1 \pm 0.2^{*}$ \\
\hline ADP/O (nmol ADP/natoms O) & $2.7 \pm 0.3$ & $2.6 \pm 0.4$ & $2.3 \pm 0.2$ & $2.4 \pm 0.1$ & $2.1 \pm 0.2$ & $1.7 \pm 0.3^{*}$ & $2.1 \pm 0.3$ & $1.9 \pm 0.3$ \\
\hline
\end{tabular}

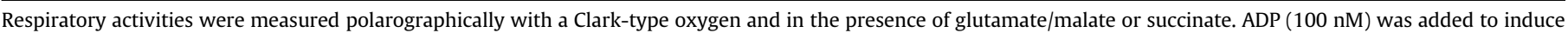

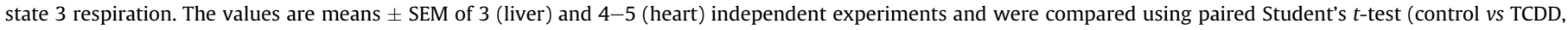
$\left.{ }^{*} p<0.05 ;{ }^{* *} p<0.01\right)$

with the exception of the TCDD-induced decreased $\Delta \Psi$ in heart mitochondria (Fig. 1A, $-224.4 \pm 2.7 \mathrm{mV}$ vs $-214.3 \pm 3.2 \mathrm{mV}$, $p=0.001$ ). The phosphorylative lag phase (Fig. 1B) was also altered by TCDD, causing an increase in the heart and a decrease in the liver, although again statistical significance was only observed in liver mitochondria for glutamate-malate $(37.0 \pm 3.6 \mathrm{~s} v \mathrm{~s} 27.0 \pm 1.7 \mathrm{~s}$, $p=0.04)$. Finally, ADP-induced depolarization was unaltered by TCDD treatment in the heart and significantly increased after treatment of liver mitochondria energized by glutamate-malate $(24.4 \pm 1.0 \mathrm{mV}$ vs $27.0 \pm 0.3 \mathrm{mV}, p=0.02)$.

\subsection{Cardiac mitochondrial carbonyl groups increases with TCDD treatment}

The second objective of the present study was to investigate whether TCDD treatment would result in increased oxidative stress in addition to altering cardiac mitochondrial function. A significant increase in protein carbonyls content was found in cardiac mitochondria from TCDD-treated rats (Fig. 2, $29120 \pm 1334$ vs $33580 \pm 781, p=0.006$ ). The presence of oxidized proteins in both groups was confirmed by the specificity of DNPH, confirming that TCDD causes cardiac mitochondrial oxidative damage. When carbonyl groups were reduced to alcohols by using $\mathrm{NaBH}_{4}$, the signal was significantly decreased, confirming once again the specificity of the method.

\subsection{MitoKATP activity is enhanced in the hearts of TCDD-treated rats}

To directly assess if mitoKATP activity was altered in TCDD-treated rats, light scattering variations were measured in mitochondrial fractions from both experimental groups as previously described (Facundo et al., 2007). Experiments were performed with succinate alone since these experimental conditions are required to optimally follow mitoKATP regulation by endogenous mitochondrial ROS (Facundo et al., 2007). The traces in Fig. 3 are representative of volume alterations due to the opening and closing of mitoKATP in heart mitochondria from control (Fig. 3A, CH) and treated rats (Fig. 3B, TH). Succinate-energized mitochondria rapidly accumulate $\mathrm{K}^{+}$, leading to osmotic water entry and to a new steady-state volume, a process requiring around $120 \mathrm{~s}$ at $37{ }^{\circ} \mathrm{C}$ to be completed (Fig. 3). In the absence of ATP (Fig. 3, control trace), mitoKATP are open and mitochondria accumulate $\mathrm{K}^{+}$and water to achieve a higher steady-state volume than the one observed in the presence of ATP (Fig. 3, ATP trace), which is explained by the inhibition of mitoKATP-dependent $\mathrm{K}^{+}$uptake. Concomitant addition of diazoxide (Fig. 3, ATP + DZX trace) reverses ATP inhibition. As expected, no effects are observed when DZX is added to mitochondria in the absence of ATP (data not show), as mitoKATP are already in the open state (Facundo et al., 2007). Effects of DZX are reversed by the addition of the mitoKATP inhibitor 5-hydroxydecanoate (Fig. 3, ATP + DZX + 5HD trace). Importantly, only $30 \mu \mathrm{M}$ DZX was used in our experimental protocol, a concentration that does not inhibit complex II activity (Dzeja et al., 2003; Kowaltowski et al., 2001). Also, no differences in mitochondrial swelling were observed in media without $\mathrm{K}^{+}$(Fig. 3A and B).

Swelling rate in cardiac mitochondria from TCDD-treated animals was significantly increased under control conditions, since $\mathrm{TH}$ swelling rate was approximately $52 \%$ higher than the one observed in the $\mathrm{CH}$ group (see Fig. 3A and $\mathrm{B}$ for typical traces, Fig. 4A for average swelling rates, $0.86 \pm 0.06-\mathrm{dAbs} / s$ vs $1.31 \pm 0.16-\mathrm{dAbs} / \mathrm{s}$, $p<0.01$ ). However, DZX was more effective in re-opening mitoKATP after ATP inhibition in TCDD-treated rats than in the control group $(0.72 \pm 0.12-\mathrm{dAbs} / s$ vs $1.12 \pm 0.25-\mathrm{dAbs} / \mathrm{s}, p<0.05)$. The data suggests that mitoKATP activity is enhanced in the hearts of TCDD-treated rats.

The activity of the channels was also measured as the total variation in swelling amplitude, which was determined as the difference between the value of light scattering detected at $120 \mathrm{~s}$ (end of assay) and $62 \mathrm{~s}$ ( $2 \mathrm{~s}$ after the addition of mitochondrial suspension). In general, swelling amplitude data reflected the same trend as the data obtained from swelling rates, although the latter appears to be more sensitive in detecting differences between experimental groups (see Fig. 4A and B). We think that the apparent lower sensitivity is due to the fact that $\mathrm{CH}$ and $\mathrm{TH}$ mitochondria reach a very similar steady-state volume, although the kinetics of volume alterations is different. When liver mitochondria from the same animals were assayed for the same parameters, not only was a minimal activity of mitoKATP in both control and treated groups measured, but also no differences were found between the two experimental groups (data not shown).

\subsection{Mitochondrial $\mathrm{H}_{2} \mathrm{O}_{2}$ release due to mitoKATP channels is decreased in the hearts of TCDD-treated rats}

MitoKATP are regulated by the mitochondrial redox state, which result in an alteration of their channel activity, contributing to a secondary regulation of mitochondrial ROS production. Because of the decreased cellular antioxidant networks in the heart (as compared with other tissues), heart mitochondria may be particularly susceptible to oxidative stress (Facundo et al., 2007), and thus mitoKATP regulation of ROS production can be an extra protective feature. We next aimed to correlate altered mitoKATP activity and ROS production by mitochondria in cardiac mitochondria from both control and TCDD-treated rats.

Under control conditions, respiratory chain $\mathrm{H}_{2} \mathrm{O}_{2}$ release rates were lower than those observed in the presence of ATP, a potential mitoKATP inhibitor (Fig. 5, CH control vs CH ATP: $5.59 \pm 0.92$ vs $9.48 \pm 0.71, p<0.001)$. The presence of ATP caused an increase in $\mathrm{H}_{2} \mathrm{O}_{2}$ release by the respiratory chain, which was higher in DMSOtreated than in TCDD-treated rats (Figs. 5, 69\% vs $43 \%$ and CH ATP vs 

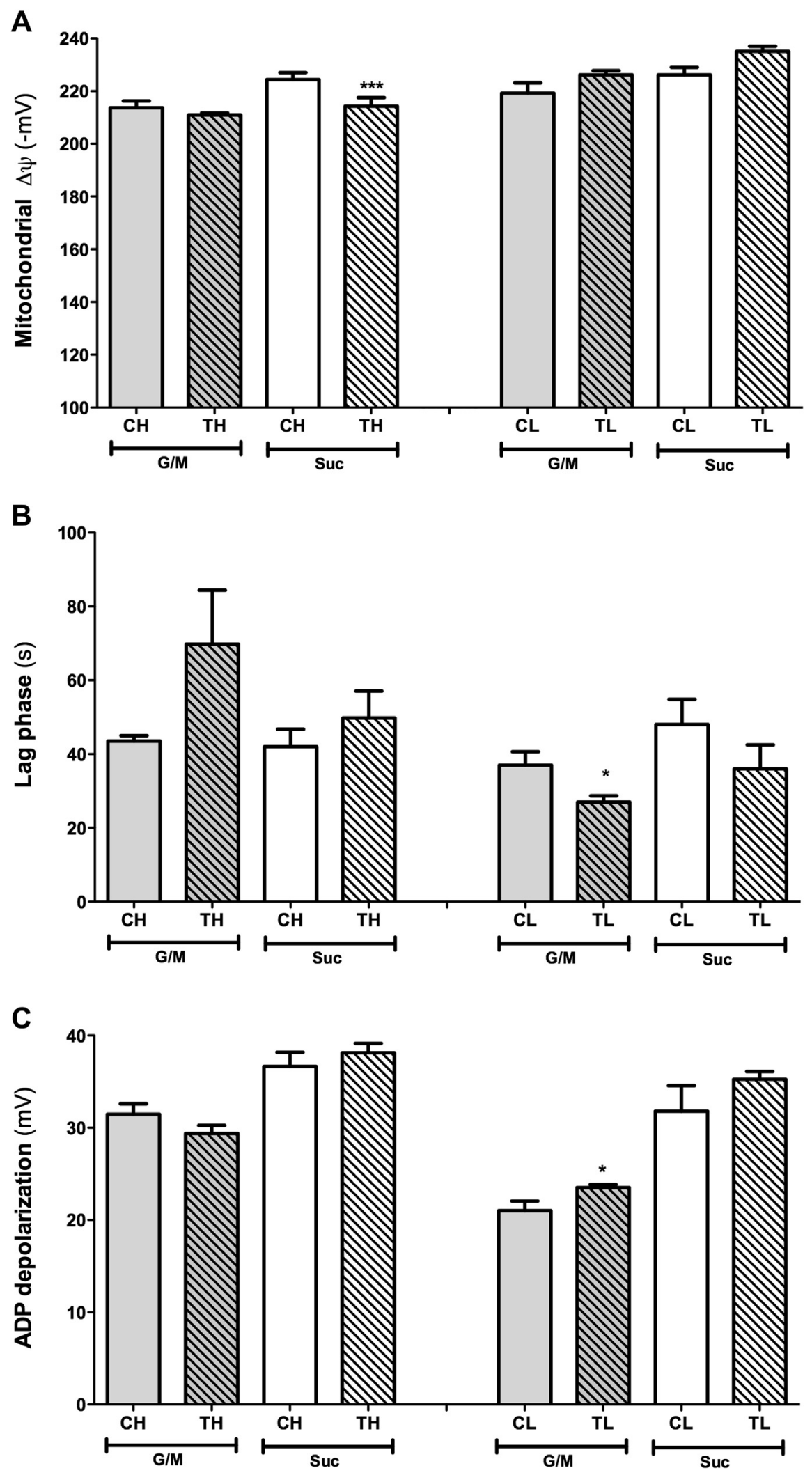

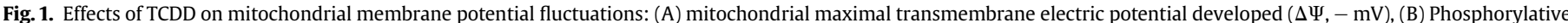

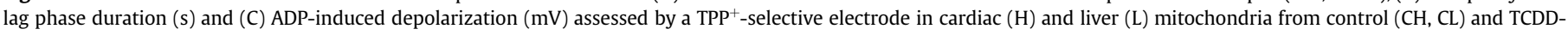

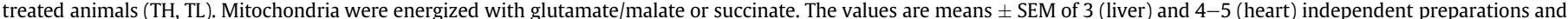
were compared using paired Student's $t$-test (control vs TCDD, ${ }^{*} p<0.05$; ${ }^{* * *} p<0.001$ ). 

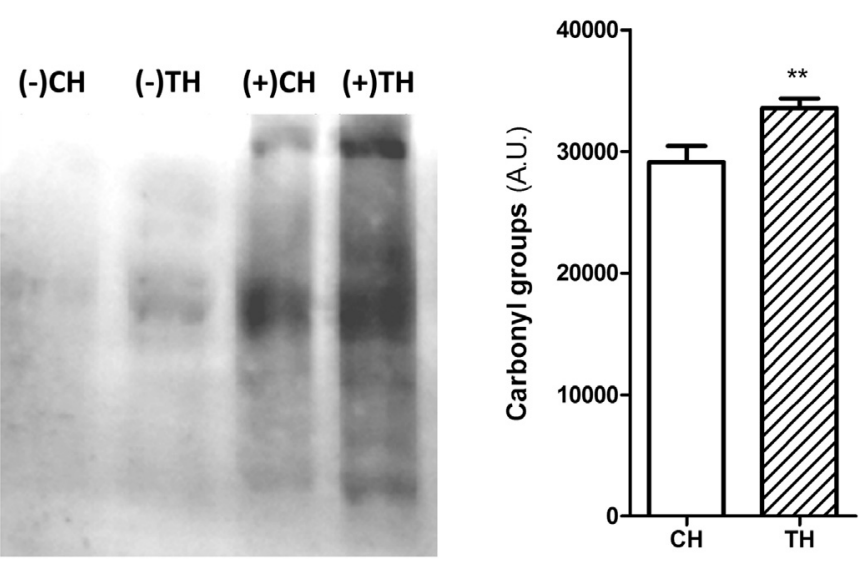

Fig. 2. Detection of carbonyl groups on mitochondria from hearts from control $(\mathrm{CH})$ and TCDD-treated animals (TH). The carbonyl content was determined by immunoblotting. Left panel, representative result with $(-)$ and $(+)$ meaning that the reaction was made in the presence and absence of DNPH as described in materials and methods. $\mathrm{TH}$, treated heart; $\mathrm{CH}$, control heart. Right panel, band density intensity of the $(+)$ lanes. The values are means \pm SEM of 4 independently experiments and were compared using paired Student's $t$-test (control vs TCDD, ${ }^{* *} p<0.01$ ).

TH ATP, $9.48 \pm 0.71$ vs $7.06 \pm 0.33, p<0.01)$. DZX decreased the production of $\mathrm{H}_{2} \mathrm{O}_{2}$ to control levels (Fig. 5, for example, $\mathrm{CH}$ ATP + DZX vs CH control, $7.23 \pm 0.50$ vs $5.59 \pm 0.92, p>0.05$ ), although the amount of $\mathrm{H}_{2} \mathrm{O}_{2}$ released by cardiac mitochondria from TCDD-treated rats was lower (CH ATP + DZX vs TH ATP + DZX, $7.23 \pm 0.50$ vs $5.16 \pm 0.49, p<0.05$ ). The agonist effect of DZX was reversed by the addition of 5-HD. In this case, the release of $\mathrm{H}_{2} \mathrm{O}_{2}$ increased to values close to those found when ATP was present (for example, CH ATP + DZX +5HD vs CH ATP, $8.71 \pm 0.72$ vs $9.48 \pm 0.71, p>0.05)$. Confirming the hypothesis that mitoKATP activity contributes to a decrease of $\mathrm{H}_{2} \mathrm{O}_{2}$ release from the respiratory chain, mitochondria incubated in $\mathrm{K}^{+}$-free, $\mathrm{Na}^{+}$-rich media presented higher $\mathrm{H}_{2} \mathrm{O}_{2}$ release rates (data not shown).

In liver mitochondria from the same experimental animals, $\mathrm{H}_{2} \mathrm{O}_{2}$ release rates were higher in the presence of ATP, although no differences existed between the control and TCDD-treated animals (data not shown).

\section{Discussion}

TCDD toxicity through AhR-independent mechanisms may involve direct effects on mitochondria, thus leading to cellular bioenergetic deficits. The major hypothesis of the current study was that TCDD causes mitochondrial dysfunction and oxidative stress in rat heart, leading to an altered regulation of mitochondrial ATPsensitive $\mathrm{K}^{+}$channels (mitoKATP), which would become more active and contribute to decrease the generation of free radicals by the mitochondrial respiratory chain. Previous studies have shown that lipid peroxidation and DNA damage can occur within $24 \mathrm{~h}$ of treatment with TCDD (Stohs et al., 1986, 1991, 1990), even after a single treatment of $50 \mu \mathrm{g} \mathrm{TCDD} / \mathrm{Kg}$ body weight. For the present study we used a high dosage of TCDD for a short interval as a model for acute TCDD high exposure. The highest dosage ever recorded in humans was $144,000 \mathrm{pg}$ TCDD/g blood fat, which corresponds to a calculated body burden of $1.6 \mathrm{mg}$ TCDD and a dosage of $25 \mu \mathrm{g} / \mathrm{kg}$ body weight (Geusau et al., 2001). Higher dosages used in rats in the present and other studies (Bagchi et al., 1993; Choi et al., 2008; Stohs et al., 1990) are justified by altered metabolism and clearance of TCDD in rats $v s$ humans, as previously described (Foster et al., 2010). We should thus take in consideration that the results from the present and above studies apply toward the effects of large acute doses of TCDD and may not be so relevant toward the normal environmental exposures at lower doses.

In our study, male Wistar rats injected with a single dose of $50 \mu \mathrm{g}$ TCDD/Kg body weight did not exhibit changes in body and organs weight $24 \mathrm{~h}$ after treatment. However, Stohs et al. (1991) reported altered liver weight after a single oral dose of $100 \mu \mathrm{g}$ TCDD/Kg body weight at 3 days post treatment and a significant decrease was reported in body weight on day 5 (Stohs et al., 1991). The differences may be related with the time elapsed posttreatment and with the dosage used.

The present work demonstrates that acute TCDD toxicity results in some measurable alterations of cardiac mitochondrial function,
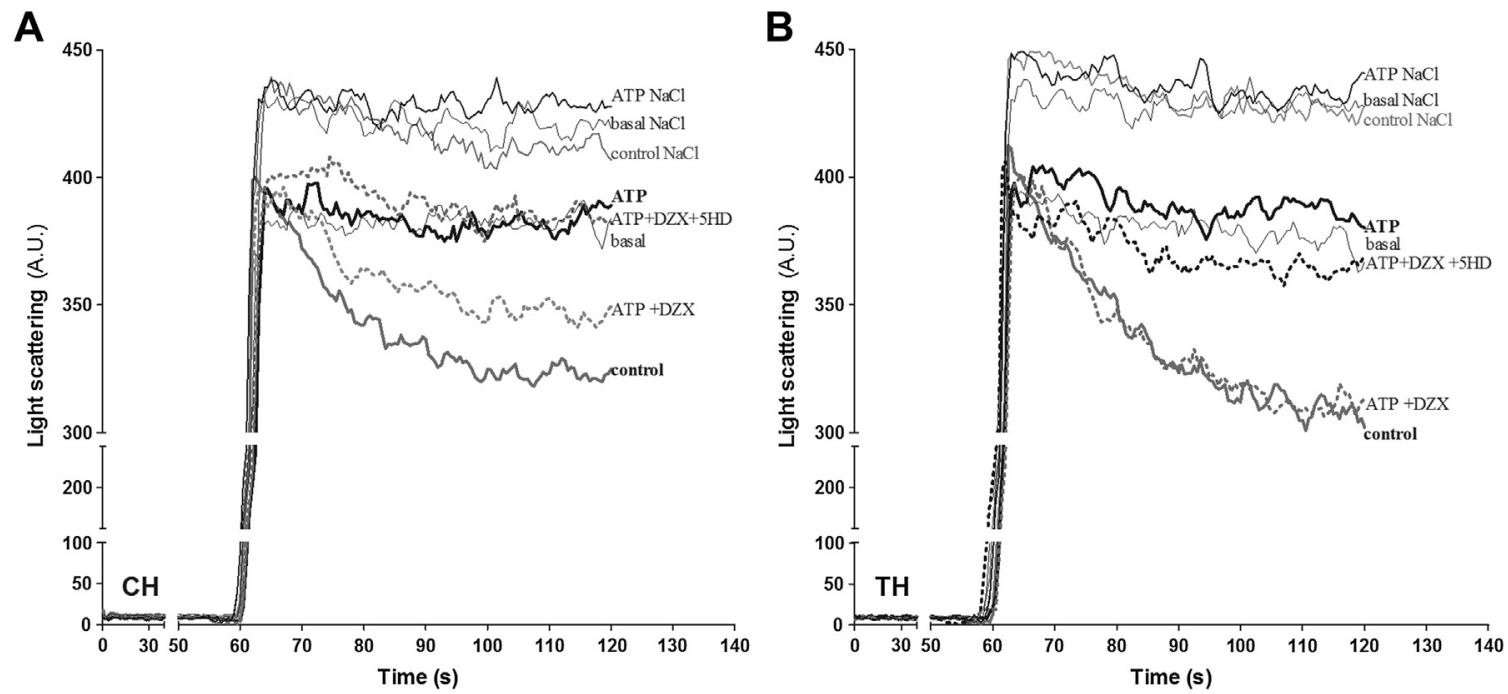

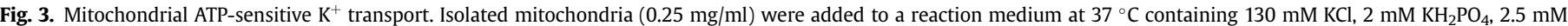

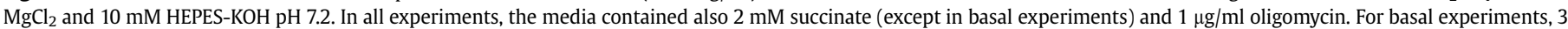

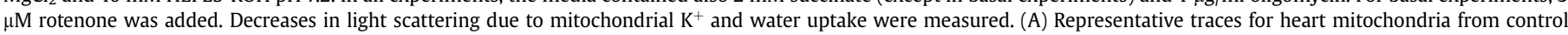

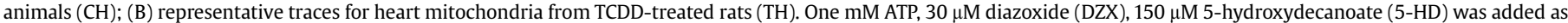

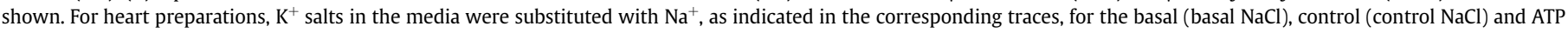
(ATP $\mathrm{NaCl}$ ) conditions. 
A

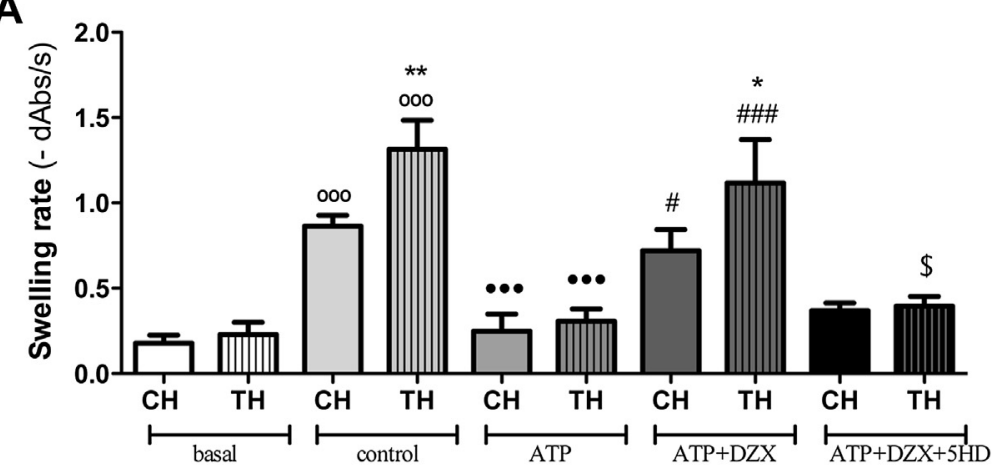

B

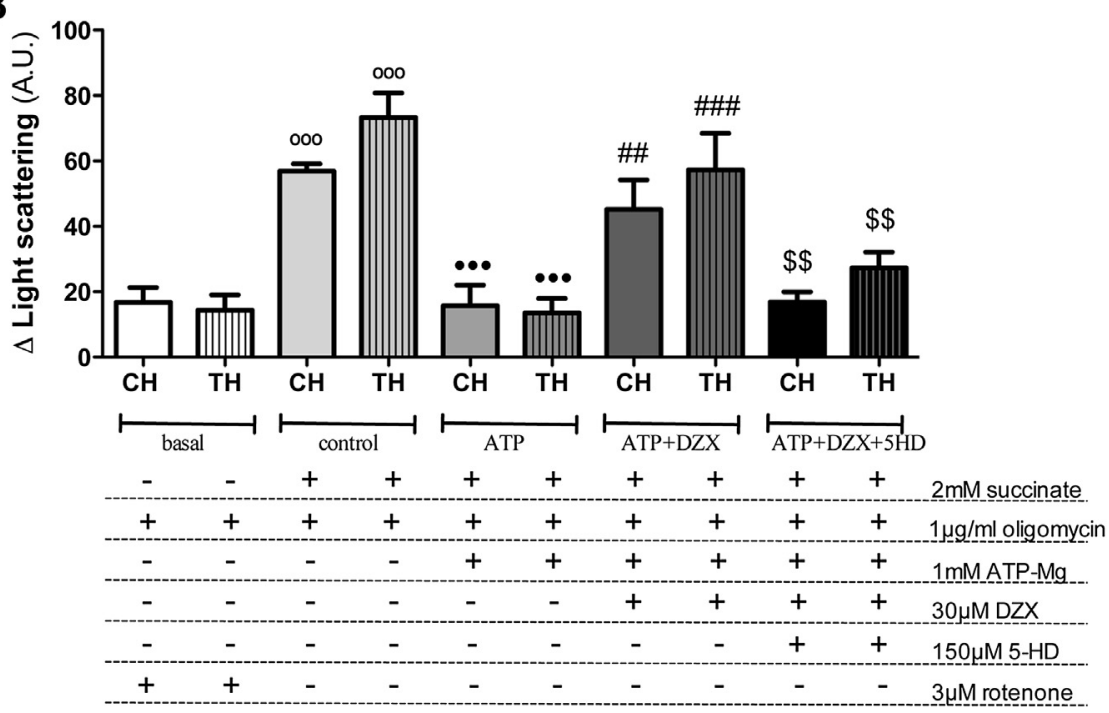

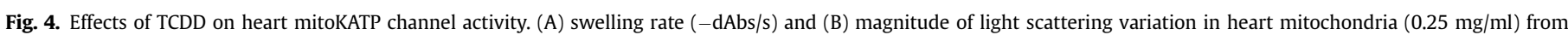

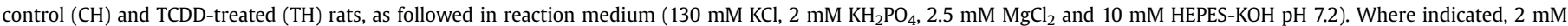

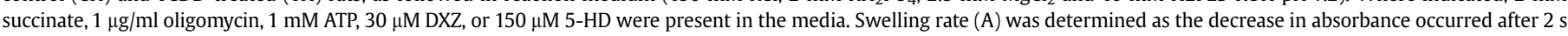

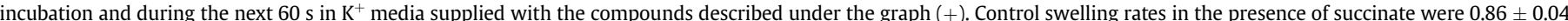

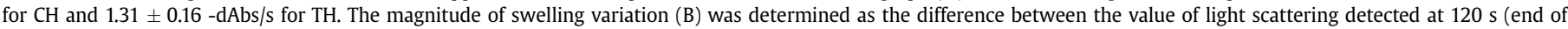

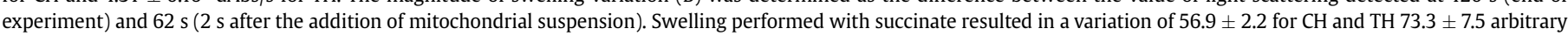

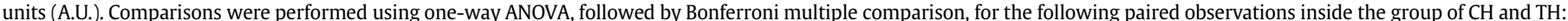

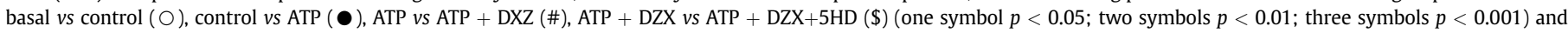

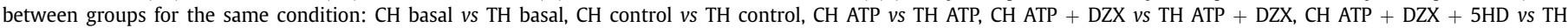
ATP + DZX + 5HD $\left({ }^{*} p<0.05 ;{ }^{* *} p<0.01 ;{ }^{* * *} p<0.001\right)$.

which appears to be multi-factorial involving both the respiratory chain and phosphorylative system. An end result of TCDD-induced cardiac mitochondrial alterations may be decreased energy production and inability to respond to stressful events by increased energy output if normal function is not restored. Alterations in cardiac mitochondrial function are accompanied by increased formation of protein carbonyls (Fig. 2), a marker for oxidative stress, which confirms that TCDD increases mitochondrial oxidative stress and damage (Senft et al., 2002).

The next step was to investigate whether increased mitochondrial oxidative stress, besides contributing to cardiac mitochondrial degeneration, can also alter the regulation of the cardiac mitoKATP. Most studies characterizing mitoKATP activity and regulation have been conducted using heart mitochondria due to their higher activity (Facundo et al., 2007). Despite the fact the majority of reports link increased mitoKATP activity to a decrease in oxidative stress (Facundo et al., 2005), others have pointed out that channel activity may actually result into increased mitochondrial free radical production (Andrukhiv et al., 2006). The fact that mitoKATP are regulated by and regulate free radical production by the respiratory chain may explain the controversy.
The most used mitoKATP opener is diazoxide (DZX), although this compound can also inhibit succinate dehydrogenase (CII) when used at concentrations higher than $100 \mu \mathrm{M}$, i.e. above the concentration needed to open mitoKATP in isolated mitochondria (Dzeja et al., 2003; Facundo et al., 2007). MitoKATP opening can be inhibited by 5-hydroxydecanoic acid (5-HD), although some authors report that 5-HD can also affect mitochondrial respiration (Lim et al., 2002) and inhibit fatty acid oxidation (Hanley et al., 2005). The effects of openers and blockers of mitoKATP appear to be modulated by the metabolic state and by the thiol redox status of mitochondria (Facundo et al., 2007; Garlid, 1996). Modulation of mitoKATP opening and closure contributes to regulate mitochondrial function. The channels are involved in the regulation of $\mathrm{K}^{+}$transport across the inner mitochondrial membrane, controlling mitochondrial transmembrane potential, matrix osmotic pressure and volume (Facundo et al., 2005). Opening of mitoKATP dissipates the inner mitochondrial membrane potential (Holmuhamedov et al., 2004), and increases matrix volume under physiological conditions or when respiration is inhibited (Kowaltowski et al., 2001).

MitoKATP opening prevents the generation of mitochondrial ROS (Forbes et al., 2001), although this idea still raises some debate. 


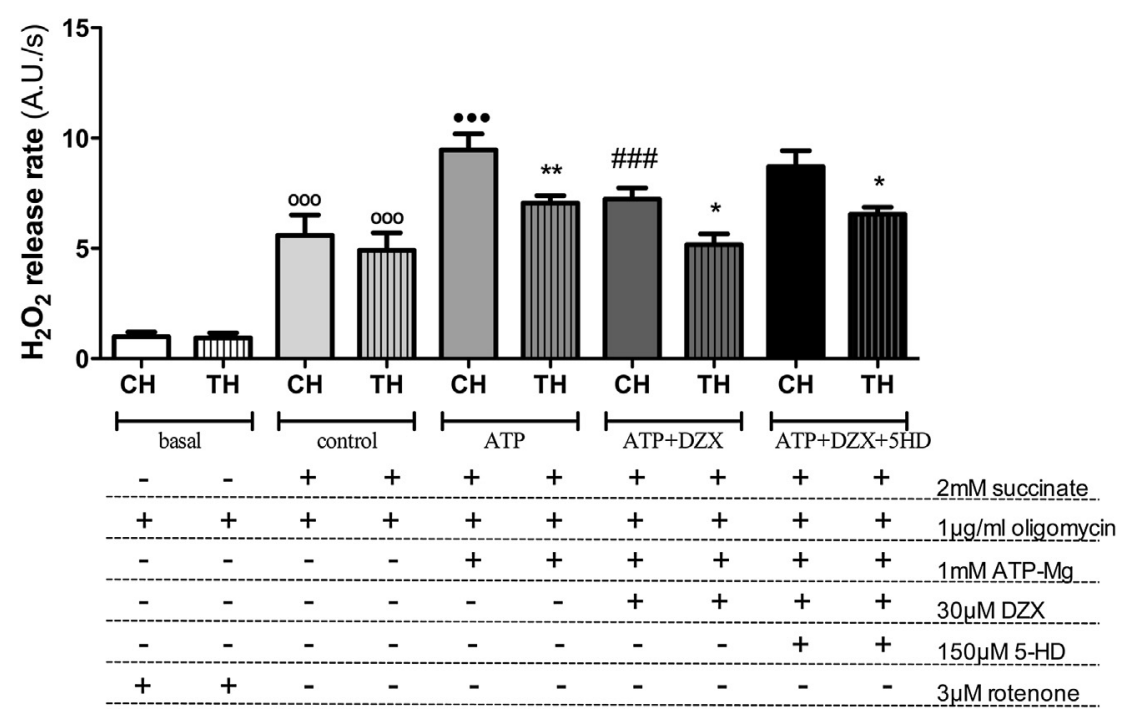

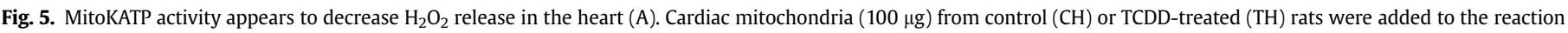

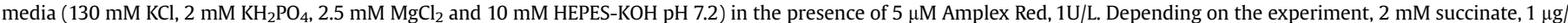

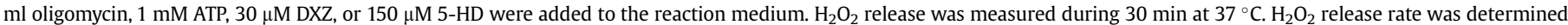

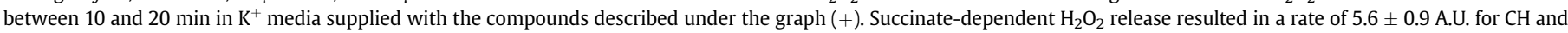

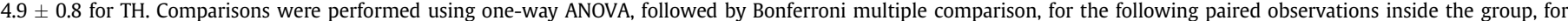

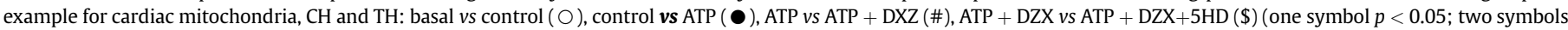

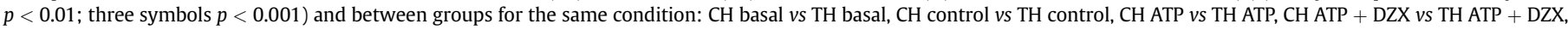
$\mathrm{CH}$ ATP $+\mathrm{DZX}+5 \mathrm{HD} v s \mathrm{TH}$ ATP $+\mathrm{DZX}+5 \mathrm{HD}\left({ }^{*} p<0.05 ;{ }^{* *} p<0.01 ;{ }^{* * *} p<0.001\right)$.

Mitochondria are the major source of reactive oxygen in most mammalian cell types, as well as a major target organelle for oxidative damage (Chomyn and Attardi, 2003). The mitoKATP may function in a manner similar to mitochondrial uncoupling proteins (Facundo et al., 2005; Hoerter et al., 2004), which are also activated by oxidative stress, decreasing membrane potential to prevent excessive mitochondrial ROS release (Facundo et al., 2005; Hoerter et al., 2004). Since mitochondrial ROS are involved in regulating pathologic and homeostatic cellular events, it is important to understand the signalling redox pathways involved in the maintenance of proper mitochondrial ROS, including during exposure to environmental chemicals such as TCDD.

By measuring variations in light scattering as means to indirectly follow mitochondrial swelling, an increased activation of mitoKATP in cardiac mitochondria from TCDD-treated rats was detected, the effect being inhibited by mitoKATP antagonists ATP and 5-HD (Figs. 3 and 4). The lack of observable mitochondrial swelling in media without $\mathrm{K}^{+}$ions (Fig. $3 \mathrm{~A}$ and $\mathrm{B}$ ) provides unequivocal evidence that this effect is related to a selective $\mathrm{K}^{+}$transport pathway that promotes mitochondrial swelling and which can be attributable to mitoKATP activity (Facundo et al., 2007). The findings appear to be in accordance with previous results indicating that the mitoKATP is a redox-sensitive channel with increased activity under more oxidative conditions (Facundo et al., 2007; Liu et al., 2002), which is demonstrated here to occur in TCDD-treated rats, as seen by increased carbonyl groups (Fig. 1). Since mitoKATP have been described to be activated when thiol groups are oxidized by exogenous ROS (Zhang et al., 2001), it is logical to predict that TCDD-induced increased ROS generation leads to the oxidation of critical thiol residues and increased open channel probability.

Using cardiac isolated mitochondria (Fig. 5), the results appear to suggest that mitochondrial ROS generation decreases when mitoKATP is in the open state. MitoKATP-modulated oxygen free radical production also exhibited the expected pharmacological response, with the addition of ATP resulting in an increase of ROS release, DZX reversing ATP inhibition and DZX effects being by its turn reversed by the addition of the mitoKATP inhibitor 5-HD. Mitochondria incubated in $\mathrm{K}^{+}$-free, $\mathrm{Na}^{+}$-containing media presented higher $\mathrm{H}_{2} \mathrm{O}_{2}$ release rates. The data suggests that the mitoKATP may be acting as a reactive oxygen species sensor that acts to decrease mitochondrial free radical generation in response to enhanced local levels of oxidants, as previously described (Facundo et al., 2007). It has been previously suggested that the effects of DZX on oxidative stress modulated by channel activity results from succinate dehydrogenase inhibition (Facundo et al., 2007); in the present study, a concentration of $30 \mu \mathrm{M}$ of DZX was used, which is three-fold lower than concentrations already described to inhibit complex II (Dzeja et al., 2003; Kowaltowski et al., 2001). The physiological mitoKATP agonist GTP decreases mitochondrial ROS release only when ATP inhibits the channel and $\mathrm{K}^{+}$is available for transport, confirming that mitoKATP activity prevents mitochondrial ROS release (Facundo et al., 2007). The protective activity of mitoKATP is also supported by the fact that mitochondrial uncoupling resulting from expressing mitochondrial uncoupling proteins (UCP) or from mild treatment with protonophores are also strongly cardioprotective, decreasing oxidative stress (Hoerter et al., 2004). Besides the possible mild mitochondrial uncoupling, activation of mitoKATP can also protect mitochondria during stressful events due to the promotion of mild mitochondrial swelling, which decreases the spatial distance between the inner and outer mitochondrial membranes, thus contributing to improve oxidative metabolism and decreasing ROS production by the mitochondrial respiratory chain (Facundo et al., 2006).

Contrary to our findings, some groups have proposed that mitoKATP activity contributes to an increase in ROS release (Andrukhiv et al., 2006). However, the increase is unrelated to the mitoKATP and attributable to interferences in ROS measurements using dichlorofluorescein in the presence of DZX (Facundo et al., 2007). In our experiments, we used the specific, high sensitivity and low noise probe Amplex Red, which is oxidized specifically by HRP-bound $\mathrm{H}_{2} \mathrm{O}_{2}$ to form the fluorescent product resorufin (Facundo et al., 2007; Zhou et al., 1997). 


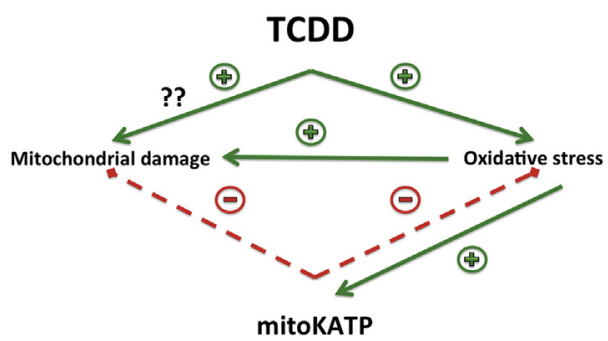

Fig. 6. Proposed interplay between cardiac mitoKATP and TCDD. From the data reported in the present work, we propose that TCDD causes mitochondrial oxidative stress, which can contribute to induce degeneration of mitochondrial function. It is also likely that TCDD causes mitochondrial dysfunction by ROS-independent factors, e.g. by altering mitochondrial membrane order. TCDD-induced oxidative stress signals through the mitoKATP, increasing their open state probability. The mitoKATP will act downstream to decrease ROS production by the respiratory chain and contribute to decrease the overall oxidative mitochondrial environment, in an attempt to adapt to TCDD increased oxidative stress. Circles with a "+" sign (full lines in green) denote a positive effect, while circles with a "-" (dashed lines in red) denote a negative effect. (For interpretation of the references to color in this figure legend, the reader is referred to the web version of this article.)

Interestingly, the fact that mitoKATP were more active in hearts from TCDD-treated rats can contribute to the decrease in mitochondrial transmembrane potential in the hearts of treated rats, although the results were only significant when succinate was used as substrate. This is hardly surprising as it has been described that the effects of mitoKATP on mitochondrial membrane potential are not easily detected with conventional methods (Facundo et al., 2006).

Despite the obvious advances in the understanding of mitoKATP as a redox sensor during dioxin-induced mitochondrial toxicity, a few limitations exist in the present work. One includes the mechanisms of TCDD-induced oxidative stress on cardiac mitochondria. It has been reported that TCDD causes oxidative stress on liver mitochondria although the authors could not exactly pinpoint the exact mechanism of increased ROS generation (Senft et al., 2002). The second limitation is to identify the links between TCDDinduced oxidative stress, increased mitoKATP activation and consequent response by decreasing ROS production by mitochondria, which to be fair is not a solo limitation of the present work, since the literature is far from an agreement (Andrukhiv et al., 2006; Facundo et al., 2007).

In conclusion, this study indicates that acute TCDD toxicity causes negative alterations on heart mitochondria and enhanced carbonylation of proteins. TCDD also caused an alteration of mitoKATP modulation, which appears to result in a decreased production of ROS by the mitochondrial respiratory chain in the treated animals. Independent of the controversy regarding the activity of mitoKATP, our results appear to suggest that the activity of these channels may decrease mitochondrial ROS release. Our data and that of others suggest that mitoKATP regulate ROS generation, thus minimizing ROS-induced oxidative damage caused by TCDD to mitochondrial structures, which is already apparent from increased protein carbonylation (Fig. 6). On the other hand, the present work highlights the need to explore alternative targets of known xenobiotics, that are known to cause oxidative stress in mitochondria, and which may alter the regulation of the mitoKATP and thus cause physiological alterations which may positively or negatively impact the outcome of toxicant interactions.

\section{Author disclosure statement}

None of the authors have any disclosures as no competing financial interests exist.

\section{Acknowledgments}

SPP and GCP are supported by a Portuguese Foundation for Science and Technology (FCT) Ph.D. fellowship (SFRH/BD/64247/ 2009 and SFRH/BD/36938/2007). The present work is supported by FCT grants PTDC-SAU-OSM-64084-2006 and PTDC/QUI-QUI/ $101409 / 2008$ (to PO) and PEst-C/SAU/LA0001/2011 (to CNC) cofunded by FEDER, COMPETE and the Portuguese National Funds. The funders had no role in study design, data collection and analysis, decision to publish, or preparation of the manuscript. The authors thank Marco Alves and Nuno Machado for technical insights and to Karen Moore for English proofreading.

\section{Appendix A. Supplementary data}

Supplementary data related to this article can be found at http:// dx.doi.org/10.1016/j.envpol.2013.05.049.

\section{References}

Aly, H.A., Khafagy, R.M., 2011. 2,3,7,8-tetrachlorodibenzo-p-dioxin (TCDD)-induced cytotoxicity accompanied by oxidative stress in rat Sertoli cells: possible role of mitochondrial fractions of Sertoli cells. Toxicol. Appl. Pharmacol. 252, 273-280.

Andrukhiv, A., Costa, A.D., West, I.C., Garlid, K.D., 2006. Opening mitoKATP increases superoxide generation from complex I of the electron transport chain. Am. J. Physiol. Heart Circ. Physiol. 291, H2067-H2074.

Bagchi, D., Shara, M.A., Bagchi, M., Hassoun, E.A., Stohs, S.J., 1993. Time-dependent effects of 2,3,7,8-tetrachlorodibenzo-p-dioxin on serum and urine levels of malondialdehyde, formaldehyde, acetaldehyde, and acetone in rats. Toxicol. Appl. Pharmacol. 123, 83-88.

Biswas, G., Srinivasan, S., Anandatheerthavarada, H.K., Avadhani, N.G., 2008. Dioxinmediated tumor progression through activation of mitochondria-to-nucleus stress signaling. Proc. Natl. Acad. Sci. U S A 105, 186-191.

Chance, B., Williams, G.R., 1955. A simple and rapid assay of oxidative phosphorylation. Nature 175, 1120-1121.

Choi, J.S., Kim, I.W., Hwang, S.Y., Shin, B.J., Kim, S.K., 2008. Effect of 2,3,7,8tetrachlorodibenzo-p-dioxin on testicular spermatogenesis-related panels and serum sex hormone levels in rats. BJU Int. 101, 250-255.

Chomyn, A., Attardi, G., 2003. MtDNA mutations in aging and apoptosis. Biochem. Biophys. Res. Commun. 304, 519-529.

Cuong, D.V., Kim, N., Joo, H., Youm, J.B., Chung, J.Y., Lee, Y., Park, W.S., Kim, E., Park, Y.S., Han, J., 2005. Subunit composition of ATP-sensitive potassium channels in mitochondria of rat hearts. Mitochondrion 5, 121-133.

Dzeja, P.P., Bast, P., Ozcan, C., Valverde, A., Holmuhamedov, E.L., Van Wylen, D.G., Terzic, A., 2003. Targeting nucleotide-requiring enzymes: implications for diazoxide-induced cardioprotection. Am. J. Physiol. Heart Circ. Physiol. 284, H1048-H1056.

Facundo, H.T., de Paula, J.G., Kowaltowski, A.J., 2005. Mitochondrial ATP-sensitive $\mathrm{K}^{+}$ channels prevent oxidative stress, permeability transition and cell death. J. Bioenerg. Biomembr. 37, 75-82.

Facundo, H.T., de Paula, J.G., Kowaltowski, A.J., 2007. Mitochondrial ATP-sensitive $\mathrm{K}^{+}$ channels are redox-sensitive pathways that control reactive oxygen species production. Free Radic. Biol. Med. 42, 1039-1048.

Facundo, H.T., Fornazari, M., Kowaltowski, A.J., 2006. Tissue protection mediated by mitochondrial $\mathrm{K}+$ channels. Biochim. Biophys. Acta 1762, 202-212.

Forbes, R.A., Steenbergen, C., Murphy, E., 2001. Diazoxide-induced cardioprotection requires signaling through a redox-sensitive mechanism. Circ. Res. 88, 802-809.

Foster, W.G., Maharaj-Briceno, S., Cyr, D.G., 2010. Dioxin-induced changes in epididymal sperm count and spermatogenesis. Environ. Health Perspect. 118, $458-464$.

Garlid, K.D., 1996. Cation transport in mitochondria-the potassium cycle. Biochim. Biophys. Acta 1275, 123-126.

Geusau, A., Abraham, K., Geissler, K., Sator, M.O., Stingl, G., Tschachler, E., 2001. Severe 2,3,7,8-tetrachlorodibenzo-p-dioxin (TCDD) intoxication: clinical and laboratory effects. Environ. Health Perspect. 109, 865-869.

Gornall, A.G., Bardawill, C.J., David, M.M., 1949. Determination of serum proteins by means of the biuret reaction. J. Biol. Chem. 177, 751-766.

Hanley, P.J., Drose, S., Brandt, U., Lareau, R.A., Banerjee, A.L., Srivastava, D.K., Banaszak, L.J., Barycki, J.J., Van Veldhoven, P.P., Daut, J., 2005. 5Hydroxydecanoate is metabolised in mitochondria and creates a rate-limiting bottleneck for beta-oxidation of fatty acids. J. Physiol. 562, 307-318.

Hassoun, E.A., Li, F., Abushaban, A., Stohs, S.J., 2000. The relative abilities of TCDD and its congeners to induce oxidative stress in the hepatic and brain tissues of rats after subchronic exposure. Toxicology 145, 103-113.

Hays, S.M., Aylward, L.L., 2003. Dioxin risks in perspective: past, present, and future. Regul. Toxicol. Pharmacol. 37, 202-217.

Hoerter, J., Gonzalez-Barroso, M.D., Couplan, E., Mateo, P., Gelly, C., CassardDoulcier, A.M., Diolez, P., Bouillaud, F., 2004. Mitochondrial uncoupling protein 
1 expressed in the heart of transgenic mice protects against ischemicreperfusion damage. Circulation 110, 528-533.

Holmuhamedov, E.L., Jahangir, A., Oberlin, A., Komarov, A., Colombini, M., Terzic, A., 2004. Potassium channel openers are uncoupling protonophores: implication in cardioprotection. FEBS Lett. 568, 167-170.

Inoue, I., Nagase, H., Kishi, K., Higuti, T., 1991. ATP-sensitive $\mathrm{K}^{+}$channel in the mitochondrial inner membrane. Nature 352, 244-247.

Jaburek, M., Yarov-Yarovoy, V., Paucek, P., Garlid, K.D., 1998. State-dependent inhibition of the mitochondrial KATP channel by glyburide and 5-hydroxydecanoate. J. Biol. Chem. 273, 13578-13582.

Kamo, N., Muratsugu, M., Hongoh, R., Kobatake, Y., 1979. Membrane potential of mitochondria measured with an electrode sensitive to tetraphenyl phosphonium and relationship between proton electrochemical potential and phosphorylation potential in steady state. J. Membr. Biol. 49, 105-121.

Knerr, S., Schrenk, D., 2006. Carcinogenicity of 2,3,7,8-tetrachlorodibenzo-p-dioxin in experimental models. Mol. Nutr. Food Res. 50, 897-907.

Kowaltowski, A.J., Seetharaman, S., Paucek, P., Garlid, K.D., 2001. Bioenergetic consequences of opening the ATP-sensitive $\mathrm{K}(+)$ channel of heart mitochondria. Am. J. Physiol. Heart Circ. Physiol. 280, H649-H657.

Lim, K.H., Javadov, S.A., Das, M., Clarke, S.J., Suleiman, M.S., Halestrap, A.P., 2002. The effects of ischaemic preconditioning, diazoxide and 5-hydroxydecanoate on rat heart mitochondrial volume and respiration. J. Physiol. 545, 961-974.

Liu, Y., Fiskum, G., Schubert, D., 2002. Generation of reactive oxygen species by the mitochondrial electron transport chain. J. Neurochem. 80, 780-787.

Mandal, P.K., 2005. Dioxin: a review of its environmental effects and its aryl hydrocarbon receptor biology. J. Comp. Physiol. B 175, 221-230.

Michalek, J.E., Tripathi, R.C., 1999. Pharmacokinetics of TCDD in veterans of Operation Ranch Hand: 15-year follow-up. J. Toxicol. Environ. Health A 57, 369-378.

Nohl, H., de Silva, D., Summer, K.H., 1989. 2,3,7,8, tetrachlorodibenzo-p-dioxin induces oxygen activation associated with cell respiration. Free Radic. Biol. Med. $6,369-374$

Noma, A., 1983. ATP-regulated $\mathrm{K}^{+}$channels in cardiac muscle. Nature 305, 147-148.

O'Rourke, B., 2004. Evidence for mitochondrial $\mathrm{K}+$ channels and their role in cardioprotection. Circ. Res. 94, 420-432.

Oliveira, P.J., Coxito, P.M., Rolo, A.P., Santos, D.L., Palmeira, C.M., Moreno, A.J., 2001. Inhibitory effect of carvedilol in the high-conductance state of the mitochondrial permeability transition pore. Eur. J. Pharmacol. 412, 231-237.

Oliveira, P.J., Marques, M.P., Batista de Carvalho, L.A., Moreno, A.J., 2000. Effects of carvedilol on isolated heart mitochondria: evidence for a protonophoretic mechanism. Biochem. Biophys. Res. Commun. 276, 82-87.

Paucek, P., Mironova, G., Mahdi, F., Beavis, A.D., Woldegiorgis, G., Garlid, K.D., 1992 Reconstitution and partial purification of the glibenclamide-sensitive, ATPdependent $\mathrm{K}^{+}$channel from rat liver and beef heart mitochondria. J. Biol. Chem. 267, 26062-26069.

Pereira, C.V., Moreira, A.C., Pereira, S.P., Machado, N.G., Carvalho, F.S., Sardao, V.A., Oliveira, P.J., 2009. Investigating drug-induced mitochondrial toxicity: a biosensor to increase drug safety? Curr. Drug Saf. 4, 34-54.

Queliconi, B.B., Wojtovich, A.P., Nadtochiy, S.M., Kowaltowski, A.J., Brookes, P.S., 2011. Redox regulation of the mitochondrial K(ATP) channel in cardioprotection. Biochim. Biophys. Acta 1813, 1309-1315.

Ray, S., Swanson, H.I., 2009. Activation of the aryl hydrocarbon receptor by TCDD inhibits senescence: a tumor promoting event? Biochem. Pharmacol. 77, $681-688$.
Robinson, C.E., Keshavarzian, A., Pasco, D.S., Frommel, T.O., Winship, D.H., Holmes, E.W., 1999. Determination of protein carbonyl groups by immunoblotting. Anal Biochem. 266, 48-57.

Rusznak, Z., Bakondi, G., Kosztka, L., Pocsai, K., Dienes, B., Fodor, J., Telek, A., Gonczi, M., Szucs, G., Csernoch, L., 2008. Mitochondrial expression of the twopore domain TASK-3 channels in malignantly transformed and non-malignant human cells. Virchows Arch. 452, 415-426.

Sardao, V.A., Oliveira, P.J., Moreno, A.J., 2002. Caffeine enhances the calciumdependent cardiac mitochondrial permeability transition: relevance for caffeine toxicity. Toxicol. Appl. Pharmacol. 179, 50-56.

Senft, A.P., Dalton, T.P., Nebert, D.W., Genter, M.B., Hutchinson, R.J., Shertzer, H.G., 2002. Dioxin increases reactive oxygen production in mouse liver mitochondria. Toxicol. Appl. Pharmacol. 178, 15-21.

Shertzer, H.G., Genter, M.B., Shen, D., Nebert, D.W., Chen, Y., Dalton, T.P., 2006. TCDD decreases ATP levels and increases reactive oxygen production through changes in mitochondrial $\mathrm{F}(0) \mathrm{F}(1)$-ATP synthase and ubiquinone. Toxicol. Appl. Pharmacol. 217, 363-374.

Siemen, D., Loupatatzis, C., Borecky, J., Gulbins, E., Lang, F., 1999. Ca ${ }^{2+}$-activated K channel of the BK-type in the inner mitochondrial membrane of a human glioma cell line. Biochem. Biophys. Res. Commun. 257, 549-554.

Stohs, S.J., Al-Bayati, Z.F., Hassan, M.Q., Murray, W.J., Mohammadpour, H.A., 1986 Glutathione peroxidase and reactive oxygen species in TCDD-induced lipid peroxidation. Adv. Exp. Med. Biol. 197, 357-365.

Stohs, S.J., Alsharif, N.Z., Shara, M.A., al-Bayati, Z.A., Wahba, Z.Z., 1991. Evidence for the induction of an oxidative stress in rat hepatic mitochondria by $2,3,7,8$ tetrachlorodibenzo-p-dioxin (TCDD). Adv. Exp. Med. Biol. 283, 827-831.

Stohs, S.J., Shara, M.A., Alsharif, N.Z., Wahba, Z.Z., al-Bayati, Z.A., 1990. 2,3,7,8 Tetrachlorodibenzo-p-dioxin-induced oxidative stress in female rats. Toxicol. Appl. Pharmacol. 106, 126-135.

Suzuki, M., Kotake, K., Fujikura, K., Inagaki, N., Suzuki, T., Gonoi, T., Seino, S Takata, K., 1997. Kir6.1: a possible subunit of ATP-sensitive $\mathrm{K}^{+}$channels in mitochondria. Biochem. Biophys. Res. Commun. 241, 693-697.

Szabo, I., Bock, J., Jekle, A., Soddemann, M., Adams, C., Lang, F., Zoratti, M. Gulbins, E., 2005. A novel potassium channel in lymphocyte mitochondria. J. Biol. Chem. 280, 12790-12798.

Szewczyk, A., Jarmuszkiewicz, W., Kunz, W.S., 2009. Mitochondrial potassium channels. IUBMB Life 61, 134-143.

U.S. EPA, 2004. Dioxin Reassessment. National Academy of Sciences (NAS) Review Draft 2004. U.S. Environmental Protection Agency, W., D.C.. EPA/600/P-00/ $001 \mathrm{Cb}$.

Veenman, L., Alten, J., Linnemannstons, K., Shandalov, Y., Zeno, S., Lakomek, M. Gavish, M., Kugler, W., 2010. Potential involvement of FOF1-ATP(synth)ase and reactive oxygen species in apoptosis induction by the antineoplastic agent erucylphosphohomocholine in glioblastoma cell lines: a mechanism for induction of apoptosis via the $18 \mathrm{kDa}$ mitochondrial translocator protein. Apoptosis 15, 753-768.

Zhang, D.X., Chen, Y.F., Campbell, W.B., Zou, A.P., Gross, G.J., Li, P.L., 2001. Characteristics and superoxide-induced activation of reconstituted myocardial mitochondrial ATP-sensitive potassium channels. Circ. Res. 89, 1177-1183.

Zhou, M., Diwu, Z., Panchuk-Voloshina, N., Haugland, R.P., 1997. A stable nonfluorescent derivative of resorufin for the fluorometric determination of trace hydrogen peroxide: applications in detecting the activity of phagocyte NADPH oxidase and other oxidases. Anal Biochem. 253, 162-168. 